\title{
Blockade of Nicotine and Cannabinoid Reinforcement and Relapse by a Cannabinoid CBI-Receptor Neutral Antagonist AM4II 3 and Inverse Agonist Rimonabant in Squirrel Monkeys
}

\author{
Charles W Schindler', Godfrey H Redhi', Kiran Vemuri ${ }^{2}$, Alexandros Makriyannis ${ }^{2}$, Bernard Le Foll ${ }^{3,4,5,6,7,8,9}$, \\ Jack Bergman ${ }^{10}$, Steven R Goldberg ${ }^{1,11}$ and Zuzana Justinova, ${ }^{*}$, \\ 'Preclinical Pharmacology Section, Behavioral Neuroscience Research Branch, Intramural Research Program, National Institute on Drug Abuse, \\ National Institutes of Health, Department of Health and Human Services, Baltimore, MD, USA; ${ }^{2}$ Center for Drug Discovery, Departments of \\ Pharmaceutical Sciences and Chemistry and Chemical Biology, Northeastern University, Boston, MA, USA; ${ }^{3}$ Translational Addiction Research \\ Laboratory, Centre for Addiction and Mental Health, University of Toronto, Toronto, ON, Canada; ${ }^{4}$ Alcohol Research and Treatment Clinic, \\ Addiction Medicine Services, Ambulatory Care and Structured Treatments, Centre for Addiction and Mental Health, Toronto, ON, Canada; \\ ${ }^{5}$ Campbell Family Mental Health Research Institute, Centre for Addiction and Mental Health, Toronto, ON, Canada; ${ }^{6}$ Department of Family and \\ Community Medicine, University of Toronto, Toronto, ON, Canada; ${ }^{7}$ Department of Pharmacology, University of Toronto, Toronto, ON, Canada; \\ ${ }^{8}$ Department of Psychiatry, Division of Brain and Therapeutics, University of Toronto, Toronto, ON, Canada; ${ }^{9}$ Institute of Medical Sciences, \\ University of Toronto, Toronto, ON, Canada; ${ }^{10}$ Preclinical Pharmacology Program, McLean Hospital, Harvard Medical School, Boston, MA, USA
}

\begin{abstract}
Nicotine, the main psychoactive component of tobacco, and $(-)-\Delta^{9}$-tetrahydrocannabinol (THC), the main psychoactive ingredient in cannabis, play major roles in tobacco and marijuana dependence as reinforcers of drug-seeking and drug-taking behavior. Drugs that act as inverse agonists of cannabinoid CBI receptors in the brain can attenuate the rewarding and abuse-related effects of nicotine and THC, but their clinical use is hindered by potentially serious side effects. The recently developed CBI-receptor neutral antagonists may provide an alternative therapeutic approach to nicotine and cannabinoid dependence. Here we compare attenuation of nicotine and THC reinforcement and reinstatement in squirrel monkeys by the $\mathrm{CBI}$-receptor inverse agonist rimonabant and by the recently developed $\mathrm{CB}$ Ireceptor neutral antagonist AM4I I3. Both rimonabant and AM4II3 reduced two effects of nicotine and THC that play major roles in tobacco and marijuana dependence: (I) maintenance of high rates of drug-taking behavior, and (2) priming- or cue-induced reinstatement of drug-seeking behavior in abstinent subjects (models of relapse). In contrast, neither rimonabant nor AM4II3 modified cocainereinforced or food-reinforced operant behavior under similar experimental conditions. However, both rimonabant and AM4I I 3 reduced cue-induced reinstatement in monkeys trained to self-administer cocaine, suggesting the involvement of a common cannabinoid-mediated mechanism in the cue-induced reinstatement for different drugs of abuse. These findings point to CBI-receptor neutral antagonists as a new class of medications for treatment of both tobacco dependence and cannabis dependence.
\end{abstract}

Neuropsychopharmacology (2016) 4I, 2283-2293; doi: I0.1038/npp.2016.27; published online I6 March 2016

\section{INTRODUCTION}

Nicotine, the main psychoactive component of tobacco, plays a major role in tobacco dependence by acting directly as a reinforcer of drug-seeking and drug-taking behavior (Henningfield and Goldberg, 1983). In rats, nicotine can initiate and maintain intravenous drug self-administration

\footnotetext{
*Correspondence: Dr Z Justinova, Preclinical Pharmacology Section, Intramural Research Program, National Institute on Drug Abuse, National Institutes of Health, Department of Health and Human Services, 251 Bayview Boulevard, Baltimore, MD 21224, USA, Tel: + I 4437402522 , Fax: + 443740 2733, E-mail: zjustino@intra.nida.nih.gov

${ }^{1}$ Deceased.
}

Received 6 October 2015; revised 8 February 2016; accepted 16 February 2016; accepted article preview online 18 February 2016
(Shoaib et al, 1997) and can support the development of conditioned place preference (Le Foll and Goldberg, 2005; Scherma et al, 2012). Nicotine can also initiate and maintain intravenous drug self-administration in nonhuman primates (Goldberg et al, 1981). In addition, administration of a priming injection of nicotine or presentation of nicotineassociated environmental cues can reinstate previously extinguished nicotine self-administration, providing an animal model of relapse (Justinova et al, 2015; Le Foll and Goldberg, 2009). These procedures offer preclinical baselines for testing potential smoking cessation medications, although caution in generalizing results from the animal models of relapse to the clinical condition has been suggested based on perceived methodological, interpretive, and translational weaknesses of these models (Katz and Higgins, 2003). Smoking is also a major route of self-administration of 
marijuana that, like cigarette smoking, is a serious public health concern. $(-)-\Delta^{9}$-tetrahydrocannabinol (THC), the main psychoactive ingredient in marijuana, plays a major role in marijuana dependence by acting as a reinforcer of drug-seeking and drug-taking behavior (Panlilio et al, 2015). Although reliable models with which to study THC reward are not available in rats, THC is intravenously selfadministrated by squirrel monkeys (Justinova et al, 2008; Tanda et al, 2000). In addition, as with other reinforcing drugs, a priming injection of THC, or presentation of THCassociated environmental cues, can restore previously extinguished THC-seeking behavior (Justinova et al, 2008, 2013).

Recent studies indicate that the endocannabinoid system plays a prominent role in the abuse-related effects of both nicotine and THC. For example, the reduction of cannabinoid CB1-receptor signaling can attenuate their rewardrelated behavioral or neurochemical effects and prevent reinstatement of drug-seeking behavior (Cohen et al, 2002; Justinova et al, 2008; Le Foll and Goldberg, 2004; Tanda et al, 1997). For example, drugs that act as inverse agonists at cannabinoid $\mathrm{CB} 1$ receptors in the brain attenuate the rewarding and reinstatement-precipitating effects of nicotine in rats (Cohen et al, 2002; Forget et al, 2009; Le Foll and Goldberg, 2004) and of THC in squirrel monkeys (Justinova et al, 2008; Tanda et al, 2000). They also attenuate reinstatement-precipitating effects of environmental cues previously associated with nicotine (Forget et al, 2009) or THC administration (Justinova et al, 2008). Notwithstanding these promising leads, further development of this class of compounds was halted because rimonabant, the first clinically available cannabinoid CB1-receptor inverse agonist, produced serious psychiatric side effects that included depression, anxiety, insomnia, and suicidal thoughts, as well as gastrointestinal side effects like nausea and diarrhea (Janero and Makriyannis, 2009; Vemuri et al, 2008; Vemuri and Makriyannis, 2015). Consequently, the European Medicines Agency called for its withdrawal and further clinical research on this class of drug ceased.

The causes of adverse psychiatric events observed with rimonabant remain unclear but perhaps may be related, at least in part, to inverse agonist activity that was well characterized in preclinical studies. For example, rimonabant and other early CB1-receptor antagonists (eg, taranabant) were shown to decrease CB1-mediated signal transduction in the absence of CB1-receptor stimulation (Landsman et al, 1997; Mato et al, 2002). More recently, CB1-receptor ligands acting as neutral antagonists (eg, AM4113, NESS0327, LH-21) have been developed that are devoid of intrinsic activity at the cellular level, and thus may have a more favorable pharmacological profile (Chambers et al, 2007; Meye et al, 2013; Pavon et al, 2006; Sink et al, 2008a, 2009, 2010a,b). For example, unlike rimonabant, the putative CB1-receptor neutral antagonist AM4113 (Sink et al, 2008a), a structurally related pyrazole analog, does not enhance forskolin-stimulated cAMP formation in vitro (Chambers et al, 2007; Sink et al, 2008a). Yet, like rimonabant, AM4113 produces anorectic effects and blocks analgesia and locomotor suppression produced by CB1-receptor agonists (Jarbe et al, 2008; Sink et al, 2008a). In other recent studies, AM4113 has also been shown not to induce anxiogenic-like reactions or conditioned taste aversion in rats (Chambers et al, 2007; Sink et al, 2008a, 2010a, b). In added contrast to inverse agonists, AM4113 neither induces vomiting in ferrets (Chambers et al, 2007; Salamone et al, 2007) nor, at anorectic doses in rats, conditioned gaping, a marker of nausea in rodents (Chambers et al, 2007; Sink et al, 2008a,b). These latter findings may further distinguish neutral antagonists from inverse agonists that often produced reports of nausea in clinical trials (Pi-Sunyer et al, 2006; Van Gaal et al, 2005).

Based on the above findings, AM4113 may have promise as a medication that retains the therapeutic efficacy of rimonabant without its psychiatric and, perhaps, gastrointestinal side effects (Storr et al, 2010; also B Le Foll, personal communication). Here, we compare behavioral effects of this novel compound with rimonabant by investigating their effects on: (1) intravenous nicotine and THC self-administration in a nonhuman primate model of drug abuse; and (2) in a model of relapse, the ability of nicotine or THC priming or nicotine- or THC-associated environmental cues to reinstate nicotine- or THC-seeking behavior after a period of abstinence. For comparison, the effects of rimonabant and AM4113 were also studied in monkeys trained to respond for food and cocaine.

\section{MATERIALS AND METHODS}

\section{Subjects}

Adult male squirrel monkeys (Saimiri sciureus) housed in individual cages in rooms in which temperature and humidity were controlled were used as subjects. Room lights were on a $12: 12$-h cycle with lights on at $0700 \mathrm{~h}$. Fresh water was continuously available. Monkeys were fed a daily food ration consisting of high-protein monkey diet (Lab Diet 5045, PMI Nutrition International, Richmond, IN) and banana-flavored food treats (Banana Softies, Bio-Serv, Frenchtown, NJ) that maintained their body weight throughout the course of the experiment (800-1200 g). Monkeys self-administering food pellets had the number of biscuits adjusted to maintain the rates of food-maintained responding at high levels ( $\sim 1$ response/s). Fresh fruits, vegetables, and environmental enrichment were provided daily. Monkeys that were studied on drug self-administration were implanted with a venous catheter for the delivery of drug. The general surgical procedure has been described in detail elsewhere (Goldberg, 1973). Briefly, a polyvinyl chloride catheter (inside diameter $0.38 \mathrm{~mm}$, outside diameter $0.76 \mathrm{~mm}$ ) was implanted in a femoral, jugular, or iliac vein. If the catheter failed during the experiment, it was removed and another catheter was implanted in an alternate vein. The distal end of the catheter was passed s.c. out through the skin in the middle of the back. Monkeys wore nylon jackets (Lomir Biomedical, Canada) at all times to protect the catheters. Catheters were flushed with saline daily and sealed with stainless steel obturators when not in use. Following a 2 -week recovery period, experiments were begun. Monkeys that were studied under a schedule of food delivery were treated similarly, except that they did not have catheter surgery and did not wear nylon jackets.

All experiments were performed at the National Institute of Drug Abuse (NIDA) and animals used in this study were maintained in facilities fully accredited by the Association for the Assessment and Accreditation of Laboratory Animal Care (AAALAC), and experiments were conducted in 
accordance with guidelines of the institutional animal care and use committee of the Intramural Research Program, NIDA, NIH, and the Guidelines for the Care and Use of Mammals in Neuroscience and Behavioral Research (National Research Council, 2003).

\section{Apparatus}

During experimental sessions, the monkeys sat in Plexiglas chairs and were loosely restrained in the seated position by a waist lock. The chairs were enclosed in ventilated soundattenuating chambers (model AC-3, Industrial Acoustics, Bronx, NY) that were provided with continuous white noise to further mask extraneous sounds. The chair contained a response lever (no. 121-05, BRS/LVE, Laurel, MD) mounted on a transparent front wall. Each press of the lever with a force greater than $0.2 \mathrm{~N}$ produced an audible click and was recorded as a response. Pairs of green and amber stimulus lights, mounted behind the transparent wall of the chair, could be illuminated and used as visual stimuli. A food trough was located in the bottom middle of the same panel as the levers. For drug self-administration the monkey's catheter was connected to polyethylene tubing that passed out of the isolation chamber where it was attached to a syringe pump. A computer located in an adjacent room using the MED Associates MED-PC software package (East Fairfield, VT) controlled the operation of the experimental events and data collection.

\section{Procedures}

Self-administration. The 1 -h sessions were typically conducted Monday-Friday. Catheters were flushed with saline and connected to the syringe pump. An injection of drug calculated to fill the dead space of the catheter was then administered. Sessions began with the illumination of the green stimulus lights. When the green stimulus lights were on, 10 responses on the response lever (FR10) led to the green light being turned off, the amber lights being turned on, and the operation of the infusion pump ( $0.2 \mathrm{ml}$ in $0.2 \mathrm{~s})$. After $2 \mathrm{~s}$, the amber lights were turned off and a timeout began where no stimulus lights were illuminated and leverpresses had no programmed consequences. After a 1-min timeout, the green stimulus lights were turned on signaling that responses on the lever could again be reinforced. Three separate groups of monkeys were trained with nicotine (30 $\mu \mathrm{g} / \mathrm{kg} /$ injection, $n=5)$, THC $(4 \mu \mathrm{g} / \mathrm{kg} /$ injection $(n=5)$, or cocaine $(30 \mu \mathrm{g} / \mathrm{kg} /$ injection, $n=3)$ before the current study. These training doses maintain maximal rates of selfadministration responding in squirrel monkeys and represent peaks of the respective inverted-U dose-effect function. Another group of food-trained monkeys $(n=4)$ were treated identically except that reinforcement for the completion of each FR was a $180 \mathrm{mg}$ banana-flavored food pellet. When responding showed $<15 \%$ variability for at least 5 consecutive sessions, we tested the effects of 5 consecutive sessions of pretreatment with rimonabant $(0.01-1 \mathrm{mg} / \mathrm{kg}$, intramuscularly (i.m.)) and AM4113 (0.3-3 mg/kg, i.m.) in each group of monkeys. The 5 -session pretreatment with the test drug was always preceded and followed by at least 3 days of vehicle pretreatment. Different doses of rimonabant and AM4113 were tested in a different order in each group. After the effects of rimonabant and AM4113 on self-administration of training dose of THC and nicotine were established, we also studied the nature of the shift of nicotine and THC dose-response functions. Selected doses of rimonabant $(0.3$ or $1 \mathrm{mg} / \mathrm{kg})$ and $\mathrm{AM} 4113(3 \mathrm{mg} / \mathrm{kg})$ were administered for one session against three doses of nicotine (studied in the following order: 100, 10, and $30 \mu \mathrm{g} / \mathrm{kg} /$ injection) and THC (studied in the following order: 4,8 , and $1 \mu \mathrm{g} / \mathrm{kg} /$ injection). Three to five sessions of vehicle pretreatment preceded each test with rimonabant or AM4113 under each nicotine and THC dose condition.

Reinstatement procedures. Before the experiments described here, the monkeys were repeatedly exposed to extinction conditions where vehicle replaced the selfadministered drug. As a result, once extinction conditions were instituted, the monkeys' responding decreased rapidly, usually within 1 day. Two types of reinstatement test were administered: priming-induced and cue-induced reinstatement. Each reinstatement test was followed by one or two extinction sessions. The reliability of reinstatement was confirmed by performing a priming-induced or cue-induced reinstatement at the beginning and the end of each of the testing sequences that are described below.

For the priming-induced reinstatement test, during extinction, responses (lever-presses, FR10) led to vehicle infusions (no drug) and continued to produce the visual stimuli previously paired with drug. Vehicle was given before each extinction session as a control for priming injections. The doses for priming $(0.1 \mathrm{mg} / \mathrm{kg}$ nicotine, $0.04 \mathrm{mg} / \mathrm{kg} \mathrm{THC}$, or $0.1 \mathrm{mg} / \mathrm{kg}$ cocaine) were selected by testing a range of doses of each reinforcer in each group of animals. The dose of each drug that produced the highest rates of drug seeking was selected for the experiments with CB1 antagonists. On test days, vehicle, rimonabant, or AM4113 was administered i.m. and one of the drug reinforcers (nicotine, THC, or cocaine) was administered (i.v.) immediately before the start of the session, during which 10 lever-presses led to vehicle infusions and presentations of visual cues previously paired with the drug. Different rimonabant $(0.03,0.1$, and $0.3 \mathrm{mg} / \mathrm{kg}$ ) and AM4113 $(0.1,0.3$, and $1 \mathrm{mg} / \mathrm{kg})$ doses were first tested in the nicotine-trained monkeys for their effects on nicotine priming-induced reinstatement. The most effective doses of rimonabant $(0.3 \mathrm{mg} / \mathrm{kg})$ and AM4113 $(1 \mathrm{mg} / \mathrm{kg})$ were then selected for all the remaining testing. These two doses were also tested in each group for their effect on saline priming to determine whether rimonabant or AM4113 alone would affect nicotine seeking. Thus, monkeys trained on nicotine were tested for nicotine, THC, and cocaine priming-induced reinstatement. The same was true for the monkeys trained on THC and cocaine.

For the cue-induced reinstatement test, during extinction, lever-presses did not produce any infusions or visual cues previously paired with drug. On test days, vehicle, rimonabant, or AM4113 was administered i.m. and completion of each FR produced vehicle infusions and presentations of visual cues. Different rimonabant $(0.03,0.1$, and $0.3 \mathrm{mg} / \mathrm{kg}$ ) and $\operatorname{AM} 4113(0.1,0.3$, and $1 \mathrm{mg} / \mathrm{kg})$ doses were first tested in the nicotine-trained monkeys for their effects on cue-induced reinstatement. The most effective doses of rimonabant 
$(0.3 \mathrm{mg} / \mathrm{kg})$ and AM4113 $(1 \mathrm{mg} / \mathrm{kg})$ were then tested in THC and cocaine groups.

Data analysis. The number of reinforcements per session represents total number of injections or food pellets delivered during each $1 \mathrm{~h}$ session. The rates of responding are expressed as responses/s averaged over the $1 \mathrm{~h}$ session, with responding and time elapsed during timeouts not included in calculations. For statistical evaluation of effects over consecutive sessions and on dose-effect functions, the mean of three sessions immediately before the experimental manipulation was used as a control value. Statistical analyses (SigmaPlot 12.5, Systat Software) were performed using one-way or two-way repeated-measures ANOVA. The post hoc pairwise comparisons were performed using Tukey's test. Differences were considered statistically significant when $p<0.05$.

Drugs. Nicotine ((-)-nicotine hydrogen tartrate) (Sigma) was dissolved in saline and $\mathrm{pH}$ was adjusted to 7.0 with diluted $\mathrm{NaOH}$ (doses expressed as base). (-)-THC (NIDA Drug Supply Program, Bethesda, MD) was dissolved in a vehicle containing $1 \%$ ethanol and $1 \%$ Tween- 80 in saline. Cocaine ((-)-Cocaine hydrochloride) (Sigma) was dissolved in saline (doses expressed as salt). The cannabinoid CB1-receptor inverse agonist rimonabant (SR141716; N-piperidino-5-(4-chlorophenyl)-1-(2,4-dichlorophenyl)-4-methylpyrazole-3-carboxamide)) (NIDA Drug Supply Program) was dissolved in 2\% Tween-80, 2\% ethanol, and saline. AM4113 ( $N$-piperidin-1-yl-2,4-dichlorophenyl$1 \mathrm{H}$-pyrazole-3-carboxamide) was synthesized in the laboratory of Dr Alexandros Makriyannis and was dissolved in 5\% dimethyl sulfoxide (DMSO), 5\% Tween-80, and sterile water. Both rimonabant and AM4113 were injected i.m. in a volume of $0.3-0.5 \mathrm{ml} / \mathrm{kg}$. Rimonabant was administered $60 \mathrm{~min}$ and AM4113 $30 \mathrm{~min}$ before the session.

\section{RESULTS}

\section{Effect of Rimonabant and AM4113 on Self-Administration}

Monkeys responded to receive near the maximum number of nicotine reinforcers $(30 \mu \mathrm{g} / \mathrm{kg}$ injections) before the administration of either rimonabant or AM4113 (Figure 1a and d, averaged $51.7 \pm 1.04$ injections per session). Response rates were more variable than injections, but were stable over the days before antagonist administration (Figure $1 \mathrm{~b}$ and e, averaged $1.31 \pm 0.1$ responses/s). Rimonabant dosedependently reduced the number of nicotine injections (Figure 1a, $\mathrm{F}_{3,30}=13.16, p=0.005$ ) and self-administration response rate (Figure $1 \mathrm{~b}, \mathrm{~F}_{3,30}=9.02, p=0.012$ ). These effects were significant for all 5 days of treatment at the highest dose of rimonabant (all p's $<0.001$ ). Following rimonabant treatment, both response rates and the number of injections rapidly recovered to the pre-rimonabant levels. Pretreatment with rimonabant $(1 \mathrm{mg} / \mathrm{kg})$ shifted the nicotine dose-response functions down and to the right (Figure 1c; injections: $\mathrm{F}_{2,8}=38.78, p<0.001$, response rates not shown: $\left.\mathrm{F}_{2,8}=57.57, p<0.001\right)$. The effects of the neutral antagonist AM4113 were similar to rimonabant (Figures $1 \mathrm{~d}$ and e; $\mathrm{F}_{2,20}=10.40, p=0.03$ ), with the highest dose of AM4113 significantly reducing injections across all 5 days of treatment (all p's $<0.001)$ and all three pretreatment doses reduced response rate (all $p$ 's $<0.05$ ). As with rimonabant, injections and response rate recovered rapidly once treatment was discontinued. AM4113 was less potent than rimonabant, with a $3 \mathrm{mg} / \mathrm{kg}$ dose required to reduce nicotine injections in comparison with the 0.3 to $1.0 \mathrm{mg} / \mathrm{kg}$ dose of rimonabant that significantly reduced the number of injections. Pretreatment with AM4113 (3 mg/kg) also shifted the nicotine dose--response functions down and to the right (Figure 1f; injections: $F_{2,8}=39.43, p<0.001$, response rates not shown: $\mathrm{F}_{2,8}=28.75, p<0.001$ ).

Similar effects were seen with both rimonabant and AM4113 when THC was being self-administered. THC $(4 \mu \mathrm{g} / \mathrm{kg}$ injections) maintained high levels of responding (averaged $46.51 \pm 0.82$ injections per session at a rate of $0.80 \pm 0.06$ responses/s) and pretreatment with rimonabant reduced the injections per session in a dose-dependent manner (Figure $2 \mathrm{a}, \mathrm{F}_{2,20}=26.91, p=0.005$ ). Response rates were also reduced significantly by rimonabant (Figure $2 \mathrm{~b}$, $\left.\mathrm{F}_{2,20}=114.89, \quad p<0.001\right)$. Pretreatment with rimonabant $(0.3 \mathrm{mg} / \mathrm{kg})$ shifted the THC dose-response functions down and to the right (Figure 2c; injections: $\mathrm{F}_{2,4}=21.42, p=0.007$, response rates not shown: $\left.\mathrm{F}_{2,4}=15.59, p=0.013\right)$. AM4113 also significantly reduced both injections (Figure $2 \mathrm{~d}$, $p$ 's $<0.05$ ) and response rates (Figure 2e, all $p$ 's $<0.01$ ). Pretreatment with AM4113 (3 mg/kg) also shifted the THC dose-response functions down and to the right (Figure 2f; injections: $\mathrm{F}_{2,4}=19.57, p=0.009$, response rates not shown: $\mathrm{F}_{2,4}=16.97, p=0.012$ ).

The effects of both pretreatments continued throughout the 5 days of treatment. Both injections and response rates recovered after the discontinuation of both rimonabant and AM4113. Similar to results with nicotine, rimonabant appears to be slightly more potent than AM4113 in reducing THC self-administration. However, both drugs appear to be more potent in reducing THC self-administration than nicotine. Pretreatment with the $0.1 \mathrm{mg} / \mathrm{kg}$ dose of rimonabant produced only small, nonsignificant reductions in nicotine self-administration, but reduced THC selfadministration by over $50 \%$. Similarly, the $0.3 \mathrm{mg} / \mathrm{kg}$ dose of AM4113 did not significantly reduce nicotine selfadministration (all $p$ 's $>0.1$ ), but did significantly reduce THC self-administration (sessions 5-8: $p$ 's $<0.05$ ).

Neither rimonabant $(0.3-3 \mathrm{mg} / \mathrm{kg}$ ) nor AM4113 (1 and $3 \mathrm{mg} / \mathrm{kg}$ ) affected the number of food pellets earned by monkeys trained with a food reinforcer (Figure $3 \mathrm{a}$ and c; rimonabant $\mathrm{F}_{2,29}=0.49, \quad p=0.64 ; \quad \mathrm{AM} 4113 \quad \mathrm{~F}_{1,15}=0.08$, $p=0.79$ ) or rates of responding (not shown; rimonabant $\mathrm{F}_{2,29}=0.22, p=0.81 ;$ AM4113 $\left.\mathrm{F}_{1,15}=0.9, p=0.41\right)$. Both drugs also did not affect the number of injections received in monkeys trained to respond for $30 \mu \mathrm{g} / \mathrm{kg}$ injections of cocaine (Figure $3 \mathrm{~b}$ and d; rimonabant: $\mathrm{F}_{5,10}=2.73, p=0.08$; AM4113: $\mathrm{F}_{5,10}=1.43, p=0.29$ ) or response rates (not shown; rimonabant: $\mathrm{F}_{5,10}=2.56, \quad p=0.1 ; \quad \mathrm{AM} 4113: \quad \mathrm{F}_{5,10}=1.98$, $p=0.17)$.

\section{Effect of Rimonabant and AM4113 on Reinstatement}

When saline was substituted for nicotine, responding dropped to a low level and pretreatment with vehicle did not produce any increases in responding (Figure 4, open bars). However, when nicotine $(0.1 \mathrm{mg} / \mathrm{kg})$, THC $(0.04 \mathrm{mg} / \mathrm{kg})$, or cocaine 

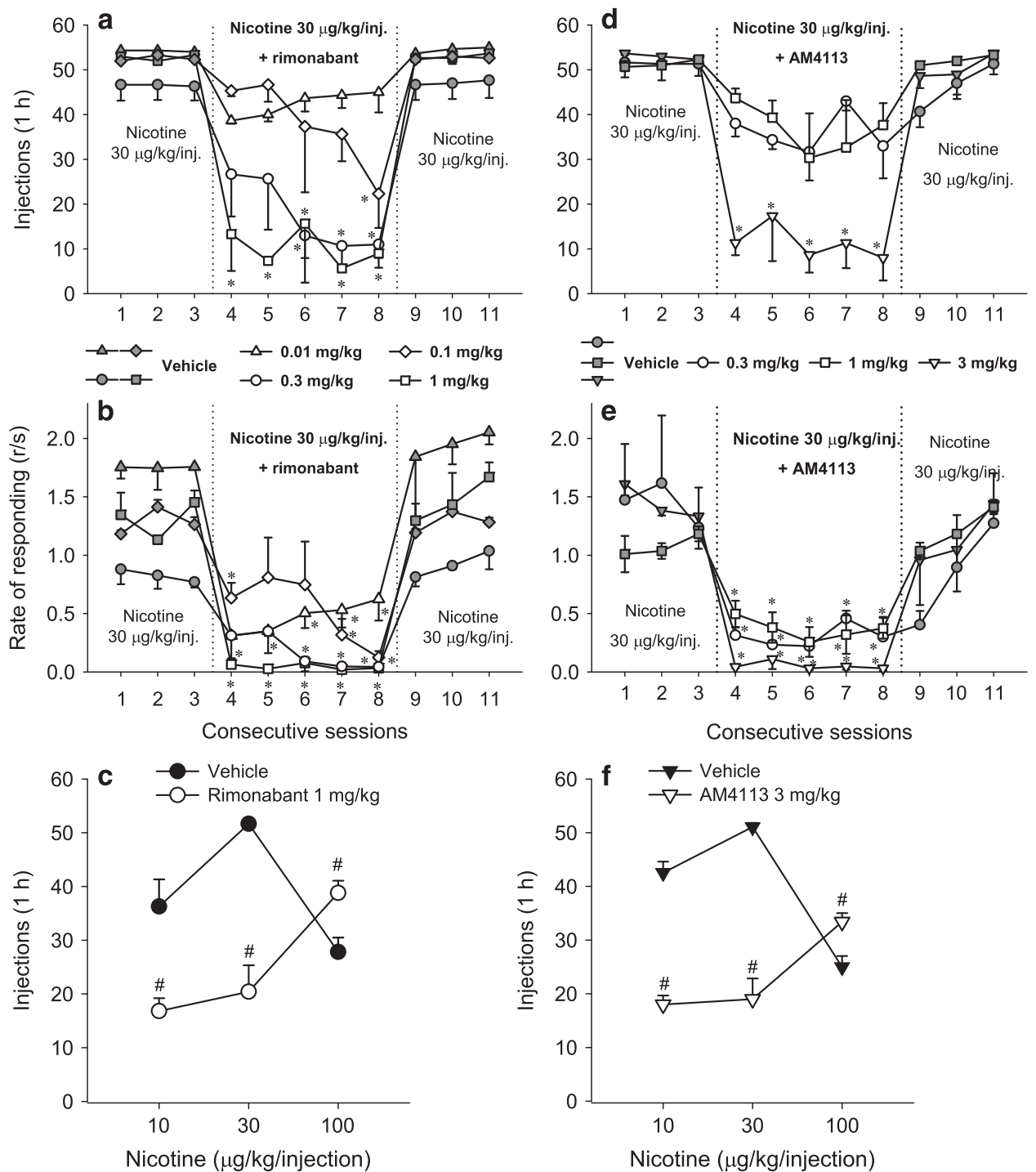

Figure I Rimonabant or AM4II3 dose-dependently blocked nicotine self-administration under a fixed-ratio 10 (FRIO) schedule in squirrel monkeys. Mean \pm SEM $(n=3)$ of nicotine injections $(30 \mu g / k g)(a, d)$ self-administered per $\mathrm{I}$ h session and overall rates of responding (b, e) are shown after i.m. pretreatment with rimonabant ((a, b) 0.0 I, 0.1, 0.3, or I mg/ $\mathrm{kg} ; 60 \mathrm{~min}$ ) or AM4 I I 3 ((d, e) 0.3, I, or $3 \mathrm{mg} / \mathrm{kg} ; 30 \mathrm{~min}$ ) for 5 consecutive sessions (sessions $4-8$ ) or vehicle (sessions I-3 and 9-| I). Rimonabant (c; I mg/kg) and AM4I I 3 (f; $3 \mathrm{mg} / \mathrm{kg}$ ) shifted nicotine dose-response curves down and to the right. Numbers of injections per session are presented as a function of injection dose of nicotine ( $(c, f) n=5)$. $*<<0.05$, different from the mean of three sessions with vehicle treatment (sessions $1-3)$. ${ }^{\#} P<0.05$, different from vehicle treatment within each nicotine dose.

$(0.1 \mathrm{mg} / \mathrm{kg})$ were given as priming injections before the session, reinstatement of the previously extinguished drug seeking was observed (Figure 4a-d, black bars; all p's $<0.001)$. The doses of nicotine, THC, and cocaine selected for the priming-induced reinstatement testing produced consistently the highest rates of responding from the dose range tested in each group of animals (Supplementary Figure S1). Rimonabant $(0.03-0.3 \mathrm{mg} / \mathrm{kg})$ and AM4113 $(0.1-1 \mathrm{mg} / \mathrm{kg})$ both dose-dependently reduced the reinstatement produced by nicotine (Figure $4 a, \mathrm{~F}_{5,10}=41.27, p<0.001$; Figure $\left.4 b, F_{5,10}=66.54, p<0.001\right)$. When the highest doses of rimonabant $(0.3 \mathrm{mg} / \mathrm{kg})$ or AM4113 $(1 \mathrm{mg} / \mathrm{kg})$ were given before a priming injection of THC, reinstatement of nicotine seeking was also clearly attenuated (Figure $4 \mathrm{c} ; \mathrm{F}_{3,9}=17.69$, $p<0.001)$. However, when rimonabant or AM4113 were given before a cocaine prime, only a nonsignificant reduction
(Figure $4 \mathrm{~d} ; p^{\prime}$ 's $>0.05$ ) in cocaine priming-induced reinstatement of nicotine seeking $\left(\mathrm{F}_{3,6}=35.72, p<0.001\right)$ was observed. Rimonabant $(0.3 \mathrm{mg} / \mathrm{kg})$ or AM4113 $(1 \mathrm{mg} / \mathrm{kg})$ did not reinstate extinguished nicotine-seeking behavior when administered before a vehicle priming injection ( $p$ 's $>0.9$ ).

The doses of rimonabant $(0.3 \mathrm{mg} / \mathrm{kg})$ and AM 4113 $(1 \mathrm{mg} / \mathrm{kg})$ that most effectively attenuated the priming effects of nicotine were also tested for their effects on THC and cocaine priming-induced reinstatement of drug seeking. The pattern of results for reinstatement testing seen in nicotinetrained monkeys was repeated for both THC- and cocainetrained monkeys. Again, substitution of vehicle for either THC or cocaine led to reductions in responding and pretreatment with vehicle did not reinstate drug seeking (open bars; Figure 4). Priming injections of nicotine, THC, or cocaine led to reinstatement of drug seeking in both 

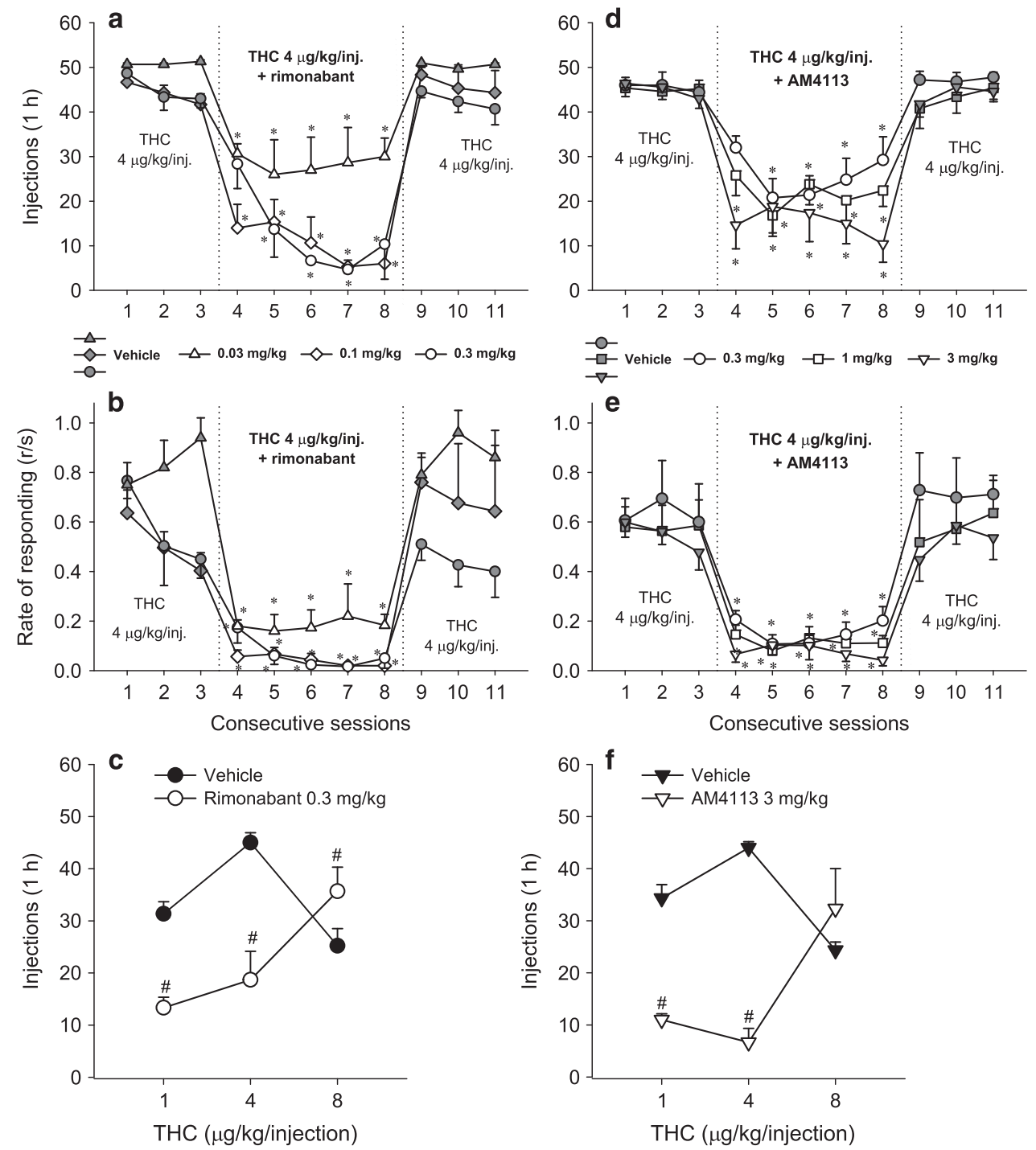

Figure 2 Rimonabant or AM4II3 dose-dependently blocked THC self-administration under a fixed-ratio IO (FRIO) schedule in squirrel monkeys. Mean \pm SEM of THC injections ( $4 \mu \mathrm{g} / \mathrm{kg})(\mathrm{a}, \mathrm{d})$ self-administered per I h session and overall rates of responding (b, e) are shown after i.m. pretreatment with rimonabant ( (a, b) $0.03,0.1$, or $0.3 \mathrm{mg} / \mathrm{kg} ; 60 \mathrm{~min} ; \mathrm{n}=3$ ) or AM4I I 3 ((d, e) 0.3 , I, or $3 \mathrm{mg} / \mathrm{kg} ; 30 \mathrm{~min} ; n=5)$ for 5 consecutive sessions (sessions $4-8$ ) or vehicle (sessions I-3 and 9-I I). Rimonabant (c; $0.3 \mathrm{mg} / \mathrm{kg}$ ) and AM4II 3 (f; $3 \mathrm{mg} / \mathrm{kg}$ ) shifted THC dose-response curves down and to the right. Numbers of injections per session are presented as a function of injection dose of $\mathrm{THC}((c, f) n=3)$. *P<0.05, different from the mean of three sessions with vehicle treatment (sessions I-3). ${ }^{\#} P<0.05$, different from vehicle treatment within each THC dose.

THC- and cocaine-trained monkeys (black bars; Figure $4 \mathrm{e}-\mathrm{g}$, all $p$ 's $<0.001$; Figure $4 \mathrm{~h}-\mathrm{j}$, all $p$ 's $<0.001)$. Both rimonabant $(0.3 \mathrm{mg} / \mathrm{kg})$ and $\mathrm{AM} 4113(1 \mathrm{mg} / \mathrm{kg})$, given as a pretreatment to nicotine or THC prime, blocked reinstatement of THC seeking (Figure 4e, $\mathrm{F}_{5,15}=46.43, p<0.001$; Figure 4f, $\left.F_{3,8}=166.54, p<0.001\right)$. Neither rimonabant $(p>0.1)$ nor AM4113 $(p>0.9)$ attenuated the cocaine priming-induced reinstatement of THC seeking (Figure 4g; $\left.\mathrm{F}_{3,9}=57.31, p<0.001\right)$. Similarly, in cocaine-trained monkeys, both rimonabant and AM4113 blocked the reinstatement of cocaine seeking produced by priming injections of nicotine (Figure $4 \mathrm{~h} ; \mathrm{F}_{5,10}=25.45, p<0.001$ ) or THC (Figure 4i; $\left.F_{3,6}=33.49, p<0.001\right)$. Rimonabant $(p>0.1)$ did not affect drug seeking induced by a priming injection of cocaine (Figure 4j; $\mathrm{F}_{3,6}=205.60, p<0.001$ ), whereas AM4113 attenuated the priming effects of cocaine (Figure $4 \mathrm{j} ; p<0.05$ ). Rimonabant $(0.3 \mathrm{mg} / \mathrm{kg})$, as well as AM4113 $(1 \mathrm{mg} / \mathrm{kg})$, caused moderate reinstatement of extinguished cocaineseeking behavior when administered before a vehicle priming injection (Figure $4 \mathrm{~h}$; both $p$ 's $<0.01$ ).

When responding no longer produced drug (nicotine, THC, or cocaine) or the cues that were previously associated with drugs, self-administration responding was deceased for all three self-administration training groups (Figure 5, open bars). Reintroduction of the response-dependent, nicotine-associated cues (injection-related and visual) reinstated drug seeking in all three groups (Figure 5, black bars). Both rimonabant (0.03$0.3 \mathrm{mg} / \mathrm{kg})$ and AM4113 (0.1-1 mg/kg) dose-dependently attenuated this cue-induced reinstatement in nicotine-trained monkeys (Figure 5a, $\mathrm{F}_{4,8}=84.76, p<0.001$; Figure 5b, $\left.\mathrm{F}_{4,8}=34.30, \quad p<0.001\right)$. The highest doses of rimonabant $(0.3 \mathrm{mg} / \mathrm{kg})$ and AM4113 $(1 \mathrm{mg} / \mathrm{kg})$ also attenuated the cueinduced reinstatement seen in THC-trained monkeys (Figure $5 c, F_{3,6}=33.81, p<0.001$ ). In contrast to the results 

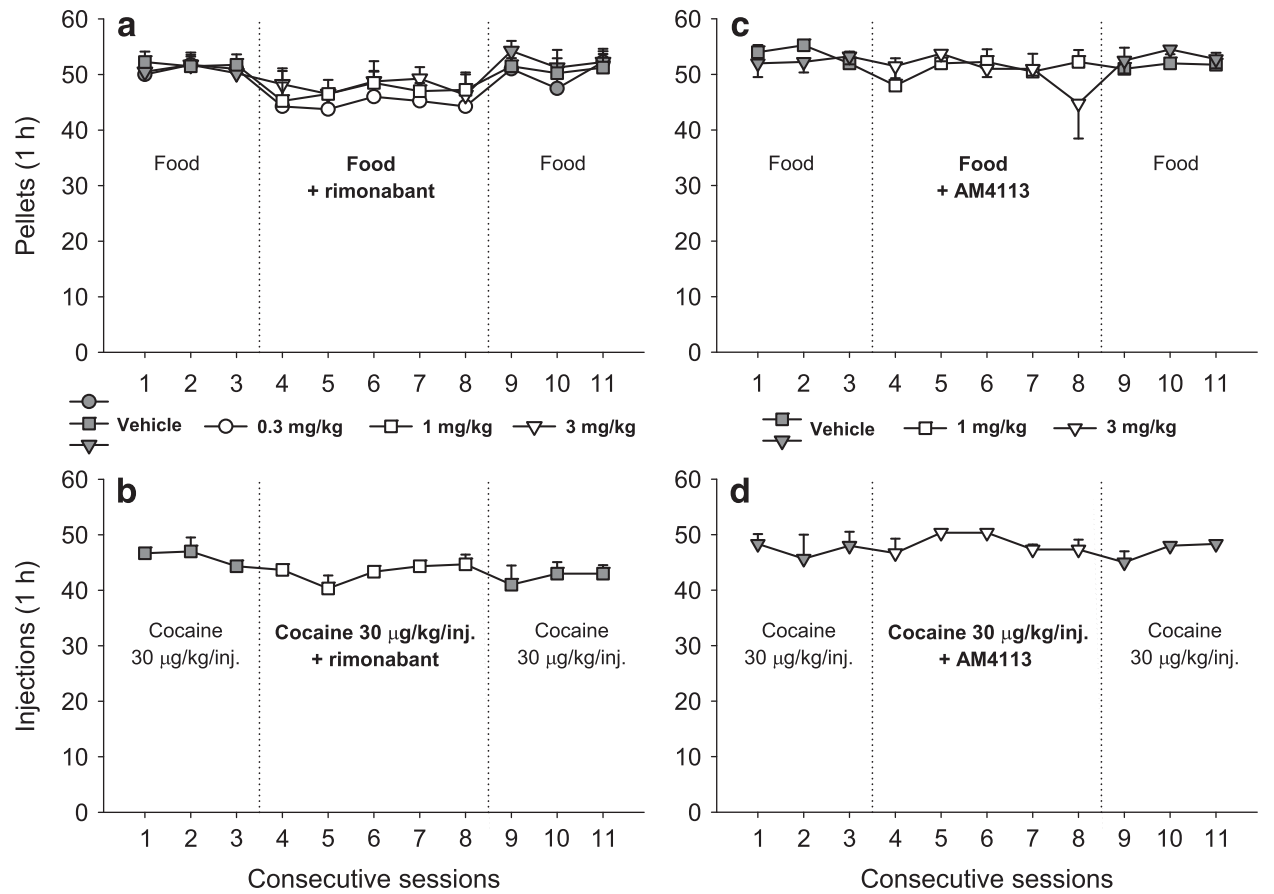

Figure 3 Rimonabant or AM4II3 did not affect food $(a, c)$ or cocaine (b, d) self-administration under a fixed-ratio 10 (FRIO) schedule in squirrel monkeys. Mean \pm SEM of food pellets $((a, c) n=4)$ or $30 \mu \mathrm{g} / \mathrm{kg}$ injections of cocaine $((b, d) n=4)$ self-administered per I h session are shown after i.m. pretreatment with rimonabant ((a) 0.3, I, or $3 \mathrm{mg} / \mathrm{kg}$; (b) I mg/kg) or AM4 I I3 ((c) I or $3 \mathrm{mg} / \mathrm{kg}$; (d) $3 \mathrm{mg} / \mathrm{kg}$ ) for 5 consecutive sessions (sessions 4-8) or vehicle (sessions I-3 and 9-I I).

seen for cocaine priming, both rimonabant and AM4113 attenuated the cue-induced reinstatement seen in cocainetrained monkeys (Figure $5 \mathrm{~d}, \mathrm{~F}_{3,6}=90.4, p<0.001$ ).

\section{DISCUSSION}

The present study shows that both the cannabinoid CB1 inverse agonist rimonabant and $\mathrm{CB} 1$ neutral antagonist AM4113 block nicotine and THC self-administration in squirrel monkeys at doses that do not affect selfadministration of cocaine or food. Attenuation of the reinforcing effects of nicotine and THC was also demonstrated by downward and rightward shifts of the doseresponse functions. Both drugs also blocked nicotine and THC priming-induced reinstatement of extinguished nicotine, THC, or cocaine seeking in monkeys. Cocaine priminginduced reinstatement of drug seeking was not consistently modified by either drug, although both rimonabant and AM4113 attenuated reinstatement by cues previously associated with self-administration of nicotine, THC, or cocaine. These results suggest that both the $\mathrm{CB} 1$ inverse agonist rimonabant and the neutral antagonist AM4113 may reduce the relapse-inducing effects of drug-associated cues across drug classes, as well as the direct priming effects of nicotine and THC regardless of previous self-administration history (nicotine, THC, or cocaine). On the other hand, these two drugs do not appear to effectively reduce the reinstatement of drug seeking following a priming injection of cocaine, regardless of drug history. Notably, neither rimonabant nor AM4113 themselves reinstated drug-seeking behavior (ie, when vehicle was the priming injection) in nicotineand THC-trained monkeys but, for reasons that are unclear, both drugs produced moderate reinstatement of drug seeking in cocaine-trained monkeys.
The present findings support previous conclusions from studies with squirrel monkeys that CB1-receptor blockade by inverse agonists can effectively reduce the rewarding effects of THC that lead to its self-administration and can prevent the reinstatement of drug-seeking behavior (Justinova et al, 2008, 2011; Tanda et al, 2000). We previously reported that THC maintained maximal responding under a fixed-ratio schedule of intravenous drug self-administration at injection doses of 2 and $4 \mu \mathrm{g} / \mathrm{kg}$ and that pretreatment with $0.3 \mathrm{mg} / \mathrm{kg}$ rimonabant markedly decreased THC self-administration (Tanda et al, 2000). In the present study, doses of 0.1 and $0.3 \mathrm{mg} / \mathrm{kg}$ rimonabant similarly decreased THC self-administration. We also previously reported that, under a second-order schedule, extinguished drug-seeking behavior in squirrel monkeys was robustly reinstated by pretreatment with $0.04 \mathrm{mg} / \mathrm{kg}$ THC and this reinstatement was blocked by rimonabant (Justinova et al, 2008), and we saw similar results in the present study under a fixed-ratio schedule. Results with AM4113 in the present study were similar to those with rimonabant in monkeys trained on THC, although AM4113 appeared to be somewhat less potent, as has been noted in previous studies with rodents (Jarbe et al, 2011). This has also been noted in a study showing that rimonabant and AM4113 antagonize the discriminativestimulus effects of CB1 receptor full agonist (AM4054) in squirrel monkeys (Kangas et al, 2013). Doses of 0.3 to $1 \mathrm{mg} / \mathrm{kg}$ of AM4113 reduced both THC self-administration and reinstatement of extinguished THC-seeking by both priming injections (nicotine or THC) and reexposure to THCassociated cues and these reductions were similar to those produced by 0.1 to $0.3 \mathrm{mg} / \mathrm{kg}$ rimonabant. In addition, AM4113, like rimonabant, reduced THC self-administration and reinstatement at doses that had no effect on food or cocaine-maintained responding. Although AM4113 and rimonabant have been shown to reduce food-maintained 

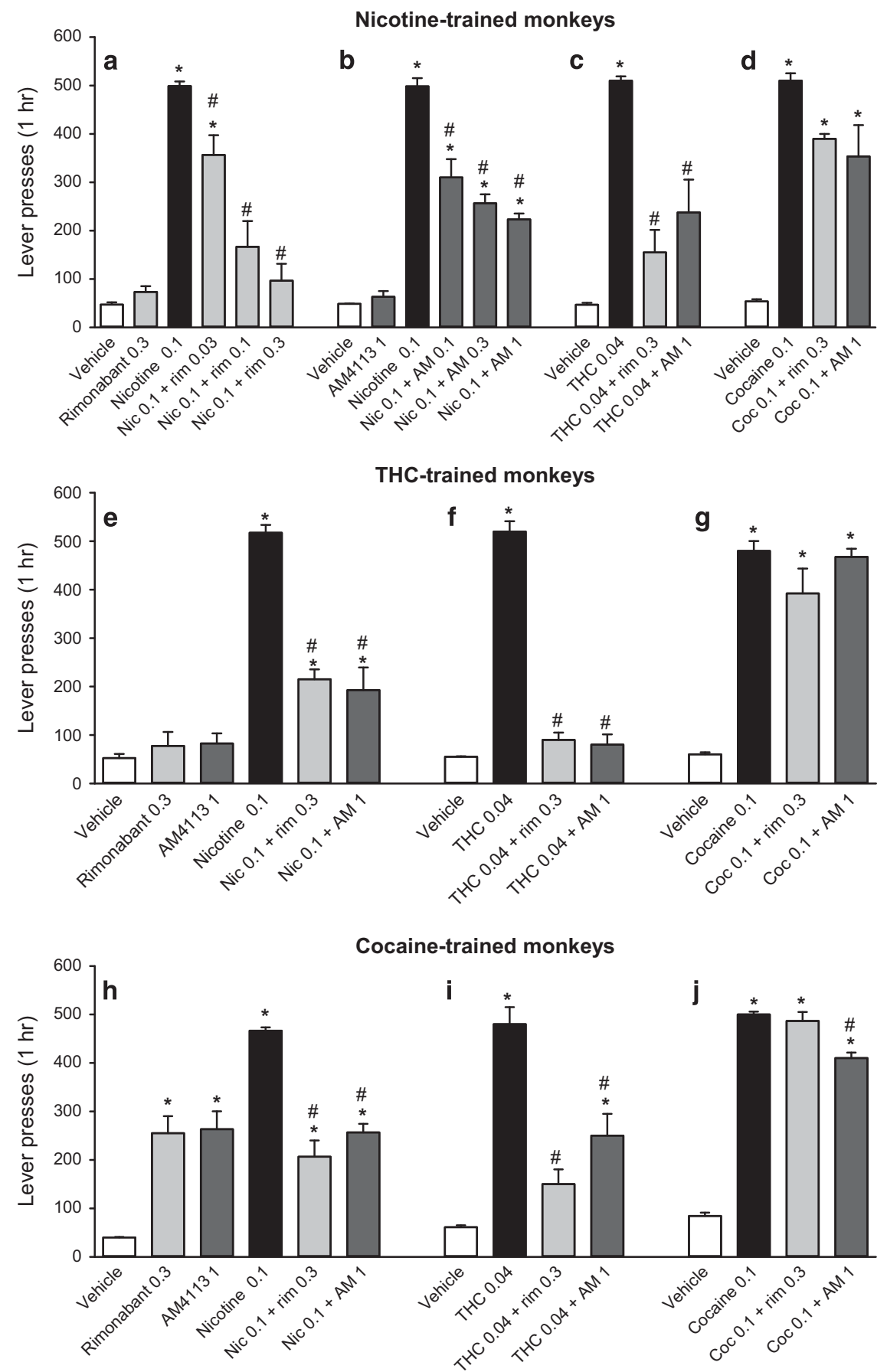

Figure 4 Effects of rimonabant or AM4II3 on priming-induced reinstatement of drug seeking in monkeys. During the extinction sessions, saline was substituted for drug (nicotine, THC, or cocaine). During test sessions, rimonabant (0.03-0.3 mg/kg), AM4 I I 3 (0. I-I mg/kg), or vehicle was injected i.m. before priming injection (i.v.) of nicotine ((a, b, e, h) $0.1 \mathrm{mg} / \mathrm{kg} ; n=3)$, THC ((c, f, i) $0.04 \mathrm{mg} / \mathrm{kg})$, cocaine $((\mathrm{d}, \mathrm{g}, \mathrm{j}) 0.1 \mathrm{mg} / \mathrm{kg})$, or vehicle. Numbers of lever-presses emitted during the I h sessions upon completion of a FRIO schedule are shown (mean \pm SEM; $n=3-4$ ). *P $<0.05$, different from the 'Vehicle' condition; ${ }^{\#} p<0.05$, different from the 'Nicotine 0.I,' 'THC 0.04,' or 'Cocaine 0.I' condition, respectively. Nic, nicotine; Coc, cocaine; rim, rimonabant; AM, AM4I I 3.

fixed-ratio responding by rats, this occurs only at much higher doses (eg, 4 to $8 \mathrm{mg} / \mathrm{kg}$ AM4113) (Sink et al, 2008a, b).

The present findings also support previous conclusions from studies in laboratory animals (Cohen et al, 2002; Diergaarde et al, 2008; Forget et al, 2005, 2009; Le Foll and Goldberg, 2004; Shoaib, 2008) and from human clinical studies (Cahill and Ussher, 2011) that CB1-receptor blockade by inverse agonists such as rimonabant can effectively reduce the rewarding effects of nicotine and prevent reinstatement of extinguished nicotine self-administration, and extend these findings with nicotine to nonhuman primates. Again, results with AM4113 in the present study were similar to those with rimonabant, although AM4113 appeared somewhat less potent. Doses of 0.3 to $1 \mathrm{mg} / \mathrm{kg}$ of AM4113 reduced 


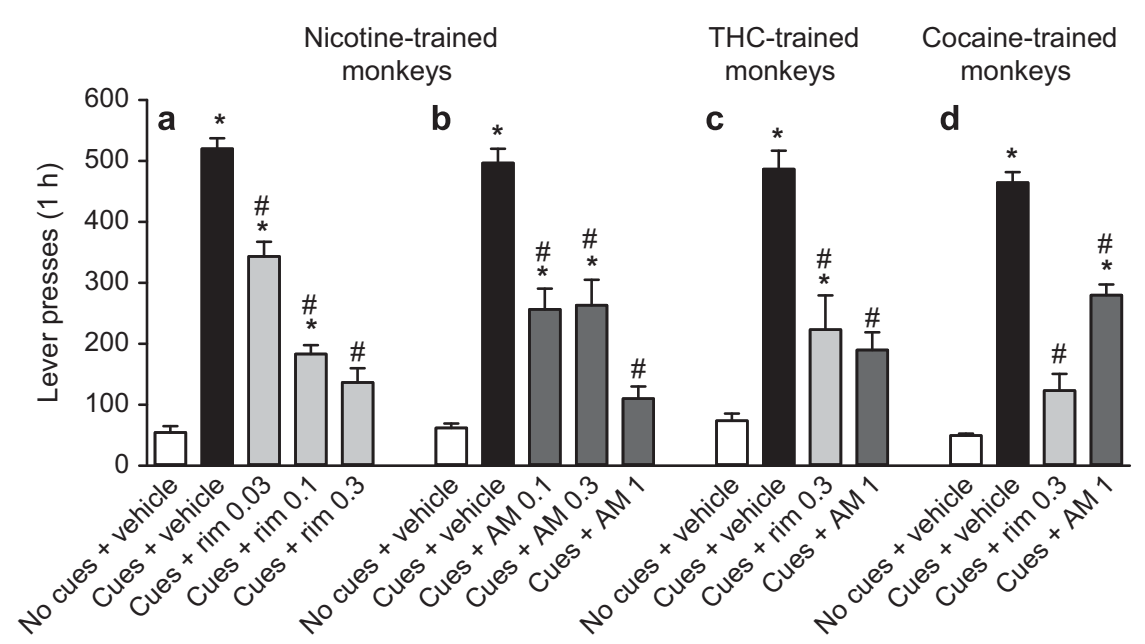

Figure 5 Effects of rimonabant or AM4II3 on cue-induced reinstatement of extinguished drug seeking in monkeys. During extinction sessions, intravenous injections and presentation of visual cues were discontinued. During test sessions, cue presentations were reinstituted and responding (FR I0) produced intravenous vehicle injections. Rimonabant (a; $0.03,0.1$, or $0.3 \mathrm{mg} / \mathrm{kg}$ ), AM4I I 3 (b; $0.1,0.3$, or I mg/ kg), or vehicle was injected i.m. before reintroduction of the cues previously associated with nicotine self-administration. Rimonabant $(0.3 \mathrm{mg} / \mathrm{kg})$ or AM4 II $3(\mathrm{I} \mathrm{mg} / \mathrm{kg})$ were also injected before reintroduction of cues previously associated with THC $(c ; n=4)$ or cocaine self-administration $(\mathrm{d} ; n=3)$. Numbers of lever-presses emitted during the I h sessions are shown (means \pm SEM; $n=3)$. $* P<0.05$, different from the 'No cues+vehicle' condition; ${ }^{*} p<0.05$, different from the respective 'Cues+vehicle' condition. Rim, rimonabant; AM, AM4I I3.

both nicotine self-administration behavior and reinstatement of extinguished nicotine-seeking behavior in abstinent monkeys by both priming injections (nicotine or THC) and reexposure to nicotine-associated cues. These reductions were similar to those produced by 0.1 to $0.3 \mathrm{mg} / \mathrm{kg}$ rimonabant. In a recent study in rats (B Le Foll, personal communication), AM4113 blocked nicotine self-administration and antagonized reinstatement to nicotine selfadministration following priming injections of nicotine as well as reexposure to nicotine-associated cues. One difference between the results seen in rodents and those shown here with primates is that in rats, the effects of AM4113 on nicotine self-administration carried over to the period following chronic administration. For squirrel monkeys, following 5 days of treatment with AM4113, nicotine selfadministration recovered quickly in the absence of the pretreatment. It should be noted that in the chronic experiments with rats, the duration of treatment was longer than 5 days, a factor that may have contributed to the persistence of its effects.

The effects of pretreatment with both rimonabant and AM4113 were specific to THC and nicotine self-administration in the current study. When self-administration responding was maintained by either food or cocaine, neither drug affected responding. Similarly, neither rimonabant nor AM4113 clearly antagonized the reinstatement of drug seeking produced by a priming injection of cocaine in nicotine-, THC-, or cocaine-trained monkeys. However, AM4113 has previously been shown to reduce the aversive properties of morphine withdrawal in rats, suggesting that effectiveness of AM4113 could extend to opiates (Wills et al, 2014). The lack of effect of rimonabant on cocaine selfadministration in rats and monkeys has been previously demonstrated (De Vries et al, 2001; Fattore et al, 1999; Filip et al, 2006; Justinova et al, 2005; Tanda et al, 2000), but data from rodent studies suggest that rimonabant or AM251, another CB1-receptor inverse agonist (De Vries et al, 2001; Filip et al, 2006; Xi et al, 2006), can block cocaine cue- induced reinstatement in rats. Thus, the involvement of endocannabinoid signaling in abuse-related effects of cocaine remains ambiguous (Wiskerke et al, 2008). In this regard, although cocaine has not been shown to reinstate extinguished cannabinoid seeking in previous studies (Justinova et al, 2008; Spano et al, 2004), priming injections of cocaine in the present studies reinstated extinguished selfadministration responding in monkeys trained to selfadminister nicotine or THC. Moreover, priming injections of nicotine and THC reinstated drug-seeking responding in cocaine-trained monkeys-effects that could be antagonized by both rimonabant and AM4113. Taken together, these results point to similarities in the involvement of the endocannabinoid system in the reinforcing and reinstatement-related effects of nicotine and THC and, as well, the reinstatement-related effects of cocaine. However, the moderate reinstatement of drug seeking by rimonabant and AM4113 in cocaine-trained monkeys was an unexpected finding that was even more intriguing as it was observed only in monkeys with a cocaine history. We can only speculate about the underlying neurobiology and offer recent evidence that points to an altered balance of $\mathrm{CB} 1$ activity in glutamatergic and GABAergic systems after cocaine exposure playing a role in the vulnerability to cocaine abuse and addiction (Martin-Garcia et al, 2015). Martin-Garcia et al (2015) have shown that deletion of CB1 receptors on GABAergic, but not cortical glutamatergic neurons of mice, can increase the primary reinforcing effects of cocaine and cocaine-induced extracellular dopamine in the nucleus accumbens. Moreover, there is evidence from rats showing that CB1 agonists can reduce self-administration of cocaine (Fattore et al, 1999; Panlilio et al, 2007) and reverse the reward-facilitating effects of cocaine in the intracranial self-stimulation paradigm (Vlachou et al, 2008). Our finding can also indicate that the involvement of the endocannabinoid system in the reinstating (and, perhaps, relapse-related) effects of cocaine may not be simply pharmacological, but may involve more general interactions related to 
conditioning factors. Although these interactions remain to be elucidated, our findings support the idea that the endocannabinoid system plays a general role in modulating cue reactivity or conditioned reinforcement following extinction of drug-seeking behavior (De Vries and Schoffelmeer, 2005; Ward et al, 2009).

In conclusion, we demonstrate in nonhuman primate models of nicotine and THC taking and relapse that the blockade of cannabinoid CB1 receptors markedly attenuates reinforcing effects of nicotine and THC as well as the reinstatement of drug seeking induced by a priming injection of nicotine or THC, or by environmental cues previously associated with nicotine or THC self-administration. In addition, our study extends findings with the CB1 inverse agonist rimonabant to the CB1 neutral antagonist AM4113. AM4113, like rimonabant, decreased both nicotine- and THC-taking and cue- and priming-induced (by nicotine or THC) reinstatement of nicotine-, THC-, and cocaine-seeking behavior in squirrel monkeys. These findings further point to potential common mechanisms in cue-induced reinstatement across a number of self-administered drugs. Finally, CB1-receptor neutral antagonists represent a new class of medications that may be useful for the treatment of both tobacco and marijuana dependence, possibly without the undesirable side effects of their inverse agonist counterparts.

\section{FUNDING AND DISCLOSURE}

Alexandros Makriyannis and Kiran Vemuri are inventors on the US patent assigned to University of Connecticut: (US8084451; Heteropyrrole analogs acting on cannabinoid receptors) that covers structure and synthesis of AM4113. The other authors declare no conflict of interest.

\section{ACKNOWLEDGMENTS}

This study is dedicated to the memory of Dr Steven $\mathrm{R}$ Goldberg (died on 25 November 2014). AM4113 was provided by Dr Alexandros Makriyannis. Rimonabant was provided by NIDA Drug Supply Program (Bethesda, MD). We thank Dr Ira Baum and Philip White for their excellent veterinary assistance during the study. This work was supported in part by the Intramural Research Program of the National Institute on Drug Abuse, National Institutes of Health, by NIDA grants R01DA19205, R01DA31020 (to Jack Bergman), and P01DA009158, R01DA007215, R37DA023142, and R37DA003801 (to Alexandros Makriyannis).

\section{REFERENCES}

Cahill K, Ussher MH (2011). Cannabinoid type 1 receptor antagonists for smoking cessation. Cochrane Database Syst Rev: CD005353.

Chambers AP, Vemuri VK, Peng Y, Wood JT, Olszewska T, Pittman QJ et al (2007). A neutral CB1 receptor antagonist reduces weight gain in rat. Am J Physiol Regul Integr Comp Physiol 293: R2185-R2193.

Cohen C, Perrault G, Voltz C, Steinberg R, Soubrie P (2002). SR141716, a central cannabinoid $(\mathrm{CB}(1))$ receptor antagonist, blocks the motivational and dopamine-releasing effects of nicotine in rats. Behav Pharmacol 13: 451-463.

De Vries TJ, Schoffelmeer AN (2005). Cannabinoid CB1 receptors control conditioned drug seeking. Trends Pharmacol Sci 26: 420-426.
De Vries TJ, Shaham Y, Homberg JR, Crombag H, Schuurman K, Dieben $J$ et al (2001). A cannabinoid mechanism in relapse to cocaine seeking. Nat Med 7: 1151-1154.

Diergaarde L, de Vries W, Raaso H, Schoffelmeer AN, De Vries TJ (2008). Contextual renewal of nicotine seeking in rats and its suppression by the cannabinoid-1 receptor antagonist Rimonabant (SR141716A). Neuropharmacology 55: 712-716.

Fattore L, Martellotta MC, Cossu G, Mascia MS, Fratta W (1999). CB1 cannabinoid receptor agonist WIN 55,212-2 decreases intravenous cocaine self-administration in rats. Behav Brain Res 104: $141-146$.

Filip M, Golda A, Zaniewska M, McCreary AC, Nowak E, Kolasiewicz W et al (2006). Involvement of cannabinoid CB1 receptors in drug addiction: effects of rimonabant on behavioral responses induced by cocaine. Pharmacol Rep 58: 806-819.

Forget B, Coen KM, Le Foll B (2009). Inhibition of fatty acid amide hydrolase reduces reinstatement of nicotine seeking but not break point for nicotine self-administration-comparison with $\mathrm{CB}(1)$ receptor blockade. Psychopharmacology (Berl) 205: 613-624.

Forget B, Hamon M, Thiebot MH (2005). Cannabinoid CB1 receptors are involved in motivational effects of nicotine in rats. Psychopharmacology (Berl) 181: 722-734.

Goldberg SR (1973). Comparable behavior maintained under fixedratio and second-order schedules of food presentation, cocaine injection or d-amphetamine injection in the squirrel monkey. J Pharmacol Exp Ther 186: 18-30.

Goldberg SR, Spealman RD, Goldberg DM (1981). Persistent behavior at high rates maintained by intravenous selfadministration of nicotine. Science 214: 573-575.

Henningfield JE, Goldberg SR (1983). Nicotine as a reinforcer in human subjects and laboratory animals. Pharmacol Biochem Behav 19: 989-992.

Janero DR, Makriyannis A (2009). Cannabinoid receptor antagonists: pharmacological opportunities, clinical experience, and translational prognosis. Expert Opin Emerg Drugs 14: 43-65.

Jarbe TU, LeMay BJ, Olszewska T, Vemuri VK, Wood JT, Makriyannis A (2008). Intrinsic effects of AM4113, a putative neutral CB1 receptor selective antagonist, on open-field behaviors in rats. Pharmacol Biochem Behav 91: 84-90.

Jarbe TU, LeMay BJ, Vemuri VK, Vadivel SK, Zvonok A, Makriyannis A (2011). Central mediation and differential blockade by cannabinergics of the discriminative stimulus effects of the cannabinoid $\mathrm{CB} 1$ receptor antagonist rimonabant in rats. Psychopharmacology (Berl) 216: 355-365.

Justinova Z, Mascia P, Wu HQ, Secci ME, Redhi GH, Panlilio LV et al (2013). Reducing cannabinoid abuse and preventing relapse by enhancing endogenous brain levels of kynurenic acid. Nat Neurosci 16: 1652-1661.

Justinova Z, Munzar P, Panlilio LV, Yasar S, Redhi GH, Tanda G et al (2008). Blockade of THC-seeking behavior and relapse in monkeys by the cannabinoid $\mathrm{CB}(1)$-receptor antagonist rimonabant. Neuropsychopharmacology 33: 2870-2877.

Justinova Z, Panlilio LV, Secci ME, Redhi GH, Schindler CW, Cross AJ et al (2015). The novel metabotropic glutamate receptor 2 positive allosteric modulator, AZD8529, decreases nicotine selfadministration and relapse in squirrel monkeys. Biol Psychiatry 78: $452-462$.

Justinova Z, Solinas M, Tanda G, Redhi GH, Goldberg SR (2005). The endogenous cannabinoid anandamide and its synthetic analog $\mathrm{R}(+)$-methanandamide are intravenously self-administered by squirrel monkeys. J Neurosci 25: 5645-5650.

Justinova Z, Yasar S, Redhi GH, Goldberg SR (2011). The endogenous cannabinoid 2-arachidonoylglycerol is intravenously self-administered by squirrel monkeys. J Neurosci 31: 7043-7048.

Kangas BD, Delatte MS, Vemuri VK, Thakur GA, Nikas SP, Subramanian KV et al (2013). Cannabinoid discrimination and antagonism by $\mathrm{CB}(1)$ neutral and inverse agonist antagonists. J Pharmacol Exp Ther 344: 561-567. 
Katz JL, Higgins ST (2003). The validity of the reinstatement model of craving and relapse to drug use. Psychopharmacology (Berl) 168: $21-30$.

Landsman RS, Burkey TH, Consroe P, Roeske WR, Yamamura HI (1997). SR141716A is an inverse agonist at the human cannabinoid CB1 receptor. Eur J Pharmacol 334: R1-R2.

Le Foll B, Goldberg SR (2004). Rimonabant, a CB1 antagonist, blocks nicotine-conditioned place preferences. NeuroReport 15: 2139-2143.

Le Foll B, Goldberg SR (2005). Nicotine induces conditioned place preferences over a large range of doses in rats. Psychopharmacology (Berl) 178: 481-492.

Le Foll B, Goldberg SR (2009). Effects of nicotine in experimental animals and humans: an update on addictive properties. Handb Exp Pharmacol 192: 335-367.

Martin-Garcia E, Bourgoin L, Cathala A, Kasanetz F, Mondesir M, Gutierrez-Rodriguez A et al (2015). Differential control of cocaine selfadministration by GABAergic and glutamatergic CB1 cannabinoid receptors. Neuropsychopharmacology (doi: 10.1038/npp.2015.351).

Mato S, Pazos A, Valdizan EM (2002). Cannabinoid receptor antagonism and inverse agonism in response to SR141716A on cAMP production in human and rat brain. Eur J Pharmacol 443: 43-46.

Meye FJ, Trezza V, Vanderschuren LJ, Ramakers GM, Adan RA (2013). Neutral antagonism at the cannabinoid 1 receptor: a safer treatment for obesity. Mol Psychiatry 18: 1294-1301.

National Research Council (2003). Guidelines for the Care and Use of Mammals in Neuroscience and Behavioral Research. The National Academies Press: Washington, DC.

Panlilio LV, Goldberg SR, Justinova Z (2015). Cannabinoid abuse and addiction: clinical and preclinical findings. Clin Pharmacol Ther 97: 616-627.

Panlilio LV, Solinas M, Matthews SA, Goldberg SR (2007). Previous exposure to THC alters the reinforcing efficacy and anxiety-related effects of cocaine in rats. Neuropsychopharmacology 32: 646-657.

Pavon FJ, Bilbao A, Hernandez-Folgado L, Cippitelli A, Jagerovic N, Abellan G et al (2006). Antiobesity effects of the novel in vivo neutral cannabinoid receptor antagonist 5-(4-chlorophenyl)-1(2,4-dichlorophenyl)-3-hexyl-1H-1,2,4-triazole-LH 21. Neuropharmacology 51: 358-366.

Pi-Sunyer FX, Aronne LJ, Heshmati HM, Devin J, Rosenstock JRIONorth America Study Group (2006). Effect of rimonabant, a cannabinoid-1 receptor blocker, on weight and cardiometabolic risk factors in overweight or obese patients: RIO-North America: a randomized controlled trial. JAMA 295: 761-775.

Salamone JD, McLaughlin PJ, Sink K, Makriyannis A, Parker LA (2007). Cannabinoid CB1 receptor inverse agonists and neutral antagonists: effects on food intake, food-reinforced behavior and food aversions. Physiol Behav 91: 383-388.

Scherma M, Justinova Z, Zanettini C, Panlilio LV, Mascia P, Fadda $\mathrm{P}$ et al (2012). The anandamide transport inhibitor AM404 reduces the rewarding effects of nicotine and nicotine-induced dopamine elevations in the nucleus accumbens shell in rats. $\mathrm{Br} J$ Pharmacol 165: 2539-2548.

Shoaib M (2008). The cannabinoid antagonist AM251 attenuates nicotine self-administration and nicotine-seeking behaviour in rats. Neuropharmacology 54: 438-444.

Shoaib M, Schindler CW, Goldberg SR (1997). Nicotine selfadministration in rats: strain and nicotine pre-exposure effects on acquisition. Psychopharmacology (Berl) 129: 35-43.

Sink KS, McLaughlin PJ, Wood JA, Brown C, Fan P, Vemuri VK et al (2008a). The novel cannabinoid CB1 receptor neutral antagonist AM4113 suppresses food intake and food-reinforced behavior but does not induce signs of nausea in rats. Neuropsychopharmacology 33: 946-955.
Sink KS, Segovia KN, Collins LE, Markus EJ, Vemuri VK, Makriyannis A et al (2010a). The CB1 inverse agonist AM251, but not the CB1 antagonist AM4113, enhances retention of contextual fear conditioning in rats. Pharmacol Biochem Behav 95: 479-484.

Sink KS, Segovia KN, Sink J, Randall PA, Collins LE, Correa M et al (2010b). Potential anxiogenic effects of cannabinoid CB1 receptor antagonists/inverse agonists in rats: comparisons between AM4113, AM251, and the benzodiazepine inverse agonist FG-7142. Eur Neuropsychopharmacol 20: 112-122.

Sink KS, Vemuri VK, Olszewska T, Makriyannis A, Salamone JD (2008b). Cannabinoid CB1 antagonists and dopamine antagonists produce different effects on a task involving response allocation and effort-related choice in food-seeking behavior. Psychopharmacology (Berl) 196: 565-574.

Sink KS, Vemuri VK, Wood J, Makriyannis A, Salamone JD (2009). Oral bioavailability of the novel cannabinoid CB1 antagonist AM6527: effects on food-reinforced behavior and comparisons with AM4113. Pharmacol Biochem Behav 91: 303-306.

Spano MS, Fattore L, Cossu G, Deiana S, Fadda P, Fratta W (2004). $\mathrm{CB} 1$ receptor agonist and heroin, but not cocaine, reinstate cannabinoid-seeking behaviour in the rat. $\mathrm{Br} J$ Pharmacol 143: 343-350.

Storr MA, Bashashati M, Hirota C, Vemuri VK, Keenan CM, Duncan $M$ et al (2010). Differential effects of $\mathrm{CB}(1)$ neutral antagonists and inverse agonists on gastrointestinal motility in mice. Neurogastroenterol Motil 22: 787-796, e223.

Tanda G, Munzar P, Goldberg SR (2000). Self-administration behavior is maintained by the psychoactive ingredient of marijuana in squirrel monkeys. Nat Neurosci 3: 1073-1074.

Tanda G, Pontieri FE, Di Chiara G (1997). Cannabinoid and heroin activation of mesolimbic dopamine transmission by a common mul opioid receptor mechanism. Science 276: 2048-2050.

Van Gaal LF, Rissanen AM, Scheen AJ, Ziegler O, Rossner SRIOEurope Study Group (2005). Effects of the cannabinoid-1 receptor blocker rimonabant on weight reduction and cardiovascular risk factors in overweight patients: 1-year experience from the RIOEurope study. Lancet 365: 1389-1397.

Vemuri VK, Janero DR, Makriyannis A (2008). Pharmacotherapeutic targeting of the endocannabinoid signaling system: drugs for obesity and the metabolic syndrome. Physiol Behav 93: 671-686.

Vemuri VK, Makriyannis A (2015). Medicinal chemistry of cannabinoids. Clin Pharmacol Ther 97: 553-558.

Vlachou S, Stamatopoulou F, Nomikos GG, Panagis G (2008). Enhancement of endocannabinoid neurotransmission through CB1 cannabinoid receptors counteracts the reinforcing and psychostimulant effects of cocaine. Int J Neuropsychopharmacol 11: 905-923.

Ward SJ, Rosenberg M, Dykstra LA, Walker EA (2009). The CB1 antagonist rimonabant (SR141716) blocks cue-induced reinstatement of cocaine seeking and other context and extinction phenomena predictive of relapse. Drug Alcohol Depend 105: 248-255.

Wills KL, Vemuri K, Kalmar A, Lee A, Limebeer CL, Makriyannis A et al (2014). CB1 antagonism: interference with affective properties of acute naloxone-precipitated morphine withdrawal in rats. Psychopharmacology (Berl) 231: 4291-4300.

Wiskerke J, Pattij T, Schoffelmeer AN, De Vries TJ (2008). The role of $\mathrm{CB} 1$ receptors in psychostimulant addiction. Addict Biol 13: 225-238.

Xi ZX, Gilbert JG, Peng XQ, Pak AC, Li X, Gardner EL (2006). Cannabinoid $\mathrm{CB} 1$ receptor antagonist AM251 inhibits cocaineprimed relapse in rats: role of glutamate in the nucleus accumbens. J Neurosci 26: 8531-8536.

Supplementary Information accompanies the paper on the Neuropsychopharmacology website (http://www.nature.com/npp) 